\title{
Crenças de professores em formação sobre o papel da pronúncia nas aulas de inglês
}

Beliefs of pre-service education teachers on the role of pronunciation in English classes

\author{
Andréa Lopes da Silva* \\ Universidade Federal de Pernambuco \\ Serra Talhada, Pernambuco, Brasil \\ Larissa de Pinho Cavalcanti* \\ Universidade Federal de Pernambuco \\ Serra Talhada, Pernambuco, Brasil
}

\begin{abstract}
Resumo: O presente trabalho tem como objetivo principal a investigação das crenças dos alunos de curso de licenciatura plena em Letras da UFRPE - UAST sobre o papel da pronúncia nas aulas de inglês. Este estudo visa agregar contribuições para os trabalhos acerca das crenças que tratem especificamente do papel ou ensino de pronúncia da língua inglesa. Buscamos identificar que crenças os professores em formação constroem e mantêm sobre a própria variante, se elas se relacionam ou são influenciadas pelo uso de uma variante hegemônica. Para tanto, partimos do conceito de crença em diversas áreas do conhecimento (BOTASSINI, 2015; FONTAINE, 1998; GUIMARÃES; 2010; LALLANDE, 1976; NESPOR, 1987; ROKEACH, 1968, 1976) até chegarmos às discussões que se restrinjam às crenças sobre o ensino-aprendizagem de línguas sob a perspectiva da Linguística Aplicada (BARCELOS, 2004). Com base nos trabalhos de BARCELOS (2000) e PAJARES (1992), nos dedicamos, também, à discussão sobre as crenças de professores e como elas podem influenciar a prática desses profissionais. Para a realização deste estudo realizamos 10 entrevistas com discentes da UFRPE - UAST que cursavam as disciplinas de Estágio Supervisionado Obrigatório em Língua Inglesa na referida instituição. Os resultados apontam que professores em formação do curso de Letras na UAST acreditam na importância de ensinar pronúncia, direta ou indiretamente, porém também acreditam nas variantes hegemônicas como referências.
\end{abstract}

Palavras-chave: Crenças, Professores em Formação, Ensino de Pronúncia, Língua Inglesa.

Abstract: the present article aims reports the investigation on beliefs of students at the EnglishPortuguese Teacher major at UFRPE-UAST on the role of pronunciation in English classes. The research aimed at contributing to studies on beliefs that particularly are focused on the teaching or the role of teaching pronunciation. We investigated the belief of pre-service education teachers on their own variant and whether they are related or influenced by the use of a hegemonic variant. The discussion on the concept of belief was supported by several areas of knowledge (BOTASSINI, 2015; FONTAINE, 1998; GUIMARÃES; 2010; LALLANDE, 1976; NESPOR, 1987; ROKEACH, 1968, 1976) while the specificity of beliefs linked to teaching-learning environments from the perspective of Applied Linguistics was supported by (BARCELOS, 2004). Then, absed on the works of we also discuss the beliefs of teachers of teachers and how they influence their daily practices. Data collection for the present article involved 10 interviews with students from UFRPE-UAST who were registered on Mandatory Supervised Internship (Estágio Supervisionado Obrigatório) for English Language. Results show that pre-service teachers believe that teaching pronunciation is important, either directly or indirectly, however they also believe that hegemonic variants are the best references.

Keywords: Belief; English; Pre-service teachers; Pronunciation;

\footnotetext{
*Universidade Federal de Pernambuco, doutora em linguística. E-mail: larissa.cavalcanti@ufrpe.br.

* Professora da Universidade Federal de Pernambuco, doutora em linguística. E-mail: andrealopes19@gmail.com UFRPE-UAST (Serra Talhada, Pernambuco, Brasil); larissa.cavalcanti@ufrpe.br.
} 


\section{INTRODUÇÃO}

Crer em algo faz parte da natureza do ser humano desde a sua existência acompanhando a sua evolução. Nossas crenças surgem das nossas experiências de vida em diferentes momentos e em contextos diversos. Dessa forma, as crenças costumam fundamentar nossos pensamentos e nossa percepção sobre nós mesmos, sobre o outro e sobre o mundo, influenciando nossas práticas cotidianas, fazendonos compreender como sujeitos condicionados para a ação e por consequência para a mudança.

Diante disso, entendemos que a importância de estudarmos as crenças reside no fato de que elas fazem parte da nossa construção enquanto sujeitos que pensam e agem de maneira individual ou coletiva, ou ainda enquanto sujeitos dinâmicos que assumem papeis variados, seja no campo pessoal ou profissional.

Posto isso, nosso foco aqui restringe-se especificamente às crenças desses futuros professores sobre o papel da pronúncia nas aulas de inglês, tendo em vista que esse aspecto linguístico, tão importante para situações ou experiências a serem vivenciadas em contextos comunicativos, é por vezes, negligenciado ou até mesmo excluído das aulas de inglês.

Desse modo, nossos objetivos consistem em investigar e identificar quais são essas crenças dos alunos do curso de licenciatura plena em Letras da UFRPE UAST sobre o papel do referido componente fonético-fonológico para ensino de inglês. Consideramos que a pronúncia pode influenciar a fala dos aprendizes de língua inglesa bem como a construção de significado e sentido diante da relação de interação entre falante e ouvinte. Porém, tal aspecto linguístico pode ser visto como irrelevante ou possui papel secundário, sendo também ensinado de maneira isolada.

Nosso artigo se divide em quatro tópicos que comportam discussões que vão desde o conceito de crença em diversas áreas do conhecimento (BARCELOS, 2000, 2004; BOTASSINI, 2015; FONTAINE, 1998; GUIMARÃES; 2010; LALLANDE, 1976; NESPOR, 1987; ROKEACH, 1968, 1976), seguindo para a discussão sobre o ensino de pronúncia nas aulas de inglês com enfoque nos conceitos de inteligibilidade e compreensibilidade (ALVES, 2015; DERWING \& MUNRO, 2015). O terceiro tópico volta-se para a descrição dos procedimentos realizados para a coleta de dados e o que nos forneceram as respostas para a verificação das crenças mobilizadas pelos participantes sobre o papel da pronúncia do inglês. Por fim, nas considerações finais, trazemos nossas reflexões sobre as respostas obtidas pela pesquisa.

\section{O CONCEITO DE CRENÇA}

As crenças possuem parte importante na construção e modificação do comportamento e da atuação de indivíduos, seja de forma isolada, ou enquanto integrantes de uma dada comunidade ou grupo. Segundo Villani (2008), as crenças se constituem historicamente, surgindo e evoluindo com o homem como ser que possui 
crenças a partir do momento que atua cognitivamente. Isso significa que as crenças podem influenciar o pensamento humano e desenvolver uma ideia de realidade do indivíduo que é ampliada, organizada e regulada na interação do sujeito com o meio no qual está inserido. $O$ interesse de pesquisadores de diversas áreas para a realização de estudos sobre crenças se iniciam com o conceito amparado na filosofia (FONTAINE, 1998; LALLANDE, 1976), psicologia (ROKEACH, 1968, 1976; NESPOR, 1987), até chegarmos às pesquisas educacionais que vão da matemática (PAJARES, 1992; GUIMARÃES, 2010) ao campo do ensino-aprendizagem de línguas sob a perspectiva da linguística aplicada (BARCELOS, 2000, 2004).

As crenças podem estimular nossa vida pessoal e social, regendo nossas ações. Em um estudo publicado sobre crenças de professores e a pesquisa educacional (Teacher's Beliefs and Educational Research), Pajares (1992) apresenta "crença" como um conceito difícil de ser classificado e desassociado de outros conceitos semelhantes, afirmando a aproximação das crenças e o seu entrelaçamento com termos como conhecimento, atitude, opinião, ideologia. Esses diferentes termos aplicáveis às crenças corroboram a complexidade de definirmos as crenças, não havendo um consenso principalmente em função da variedade de áreas que realizam ou realizaram estudos sobre as crenças e aos interesses dissemelhantes de pesquisadores.

Nos anos 1970, as pesquisas sobre crenças começam a (re)surgir, porém com diferentes termos. Hosenfeld (1978) utiliza o termo "mini-teorias" para se referir às crenças sobre aprendizagem de línguas dos alunos. Breen e Candlin (1980), empregavam o termo "visão do aluno" (apud BARCELOS, 2004, p. 127) para tratar das crenças. Em 1985, o termo "crenças" surge pela primeira vez na Linguística Aplicada através das pesquisas de Horwitz que elabora o BALLI (Beliefs About Language Learning Inventory) que passa a servir de modelo para o levantamento e a sistematização de crenças de professores e alunos.

No Brasil, os estudos referentes às crenças sobre a aprendizagem de línguas se iniciam somente na década de 1990. Barcelos (2004), aponta que apesar de não se encontrar menção as pesquisas sobre crenças nos anais da Associação de Linguística Aplicada do Brasil (ALAB) até o ano de 1995, teses e dissertações sobre crenças concernindo o campo da Linguística Aplicada (doravante LA) surgiram já nesse ano (BARCELOS, 1995; FÉLIX, 1999; GIMENEZ, 1994; SILVA, 2000; SILVA, 2001 apud BARCELOS, 2004) e continuam sendo de interesse de pesquisadores da LA até o tempo presente. Contudo, em 1991, o conceito de crenças já despontava no país com os trabalhos de Leffa (1991) e Almeida Filho (1993). Leffa (1991) investigou as "concepções de alunos" ao iniciarem a quinta série, enquanto Almeida Filho (1993) se propôs a pesquisar o que chamou de "cultura de aprender", conceito também utilizado por Barcelos (1995) ao investigar as crenças de graduandos em Letras. Em 1997, em congresso da ALAB, observou-se a existência de pelo menos quatro trabalhos a respeito de crenças sobre aprendizagem de línguas.

O interesse sobre os estudos de crenças na Linguística Aplicada surge quando o enfoque de pesquisas na área é posto sobre o processo de aprendizagem de línguas, 
com o aprendiz como centro do ensino-aprendizagem, que considera a necessidade de investigar suas crenças para chegarmos a um entendimento adequado do sujeito aprendiz. Assim, nos concentramos em uma concepção de crença a partir da Linguística Aplicada com foco no ensino-aprendizagem de língua inglesa e, mais especificamente, na observação do impacto positivo ou negativo que provém de crenças de professores em formação acerca do papel pronúncia nas aulas de inglês.

\subsection{CRENÇAS DE PROFESSORES E O ENSINO DE INGLÊS}

Como aludido ao final da seção anterior, é possível estudar as crenças de ensino-aprendizagem pela perspectiva de qualquer ator social envolvido, notadamente, os professores e os alunos. No que diz respeito aos professores:

as crenças dos professores são moldadas por sua história social, política, crenças culturais e práticas através de suas histórias biográficas, treinamentos pré-serviço, atividades de ensino e experiências profissionais. As crenças dos professores permeiam o conhecimento dos professores e afetam seu comportamento na sala de aula. (TSENG; IVANIC, 2006 apud VILLANI, 2008, p. 158)

As crenças dos docentes se entrelaçam, portanto, com um conjunto de experiências profissionais, e conhecimentos teóricos, resultantes da sua formação acadêmica, que podem afetar a prática docente positivo e/ou negativamente.

Ao nos referirmos à influência das crenças no ensino de línguas, principalmente o ensino de inglês, as crenças dos professores possuem, para além das experiências pessoais e profissionais e formação acadêmica, as experiências que os educadores tiveram enquanto aprendizes de inglês. De acordo com Garbuio (2006 apud VILLANI, 2008), as crenças dos professores de línguas originadas a partir das suas experiências de aprendizagem podem influir nos resultados e preferências reconhecidas na prática.

Reconhecemos, assim, que as crenças sobre ensino e aprendizagem de línguas, se referem, majoritariamente, à própria língua e à ideia que se tem sobre o que significa aprender e ensinar uma língua.

Os estudos sobre crenças de professores são classificados por Barcelos (2000), como um tópico mais ou menos recente no que diz respeito ao ensino de línguas, tendo sido o estudo de Lortie (1975) um dos precursores das pesquisas sobre tal tema. A partir da metade dos anos 1970, o ponto de vista dos professores passa a ser considerado quando suas ações, comportamentos e atitudes são analisadas e discutidas. A partir das pesquisas sobre crenças de professores, denominadas por Freeman e Johnson (1998) de conhecimento em ação (knowledge in action) ou raciocínio/pensamento em ação (reasoning-in-action), "a ênfase é [colocada] no entendimento de como a interpretação do professor e os processos cognitivos são incorporados na sua prática"1 (JOHNSON, 1999, apud BARCELOS, 2000).

\footnotetext{
1 No original: "The emphasis is on understanding how teacher's interpretations and cognitive processes are embedded in their practice”. Tradução nossa.
} 
Essas crenças, segundo Barcelos, explicariam o porquê e o modo como os docentes agem em sala de aula e os motivos pelos quais fazem ou deixam de fazer certas coisas. Professores em formação, os futuros profissionais docentes, que serão nosso foco, podem se sentir inferiorizados pela inexperiência em sala e não se deixarem guiar na prática pelas próprias crenças, mas, por outro lado, podem também estar sujeitos à atuarem conforme as crenças provenientes da formação acadêmica somente. Desse modo, ratificamos o conceito de crenças que se originam, se moldam e mudam em conformidade com as experiências (pessoais, acadêmicas, profissionais etc.) e o contexto no qual profissionais atuantes e futuros profissionais se encontram ou se encontrarão no futuro.

Para finalizar, é importante considerarmos ainda que as crenças dos alunos também podem influenciar a prática desses profissionais docentes ainda em formação, considerando que a dinâmica de ensino-aprendizagem se fortalece também quanto às experiências e expectativas dos aprendizes. Isso faz com que eles participem mais ativamente no contexto de sala de aula ou, se desencorajarem, com relação ao aprendizado, dependendo do quanto suas crenças em combinação ou interação com as dos professores possam impactar essa relação de ensinoaprendizagem de forma negativa ou positiva.

\section{PRONÚNCIA NAS AULAS DE INGLÊS COMO LÍNGUA ADICIONAL}

A partir do conceito de crença apresentado em diversas áreas do conhecimento e, também, das crenças relacionadas diretamente ao ensinoaprendizado de língua, nos dedicaremos ao papel e ao ensino de pronúncia nas aulas de inglês como língua adicional neste capítulo.

Devido ao grande número de conteúdos e habilidades a serem contemplados nas aulas de língua inglesa na escola pública, em sua maioria, referentes à memorização de vocabulário e regras gramaticais, o ensino de pronúncia parece ocupar um lugar pouco ou nada relevante, sendo, por vezes, negligenciado ou excluído por completo. Isso se deve, a princípio, ao fato de o ensino de inglês nas escolas públicas ainda estar majoritariamente pautado em métodos tradicionais que costumam desconsiderar a importância do ensino de pronúncia. Por outro lado, a preocupação com a oralidade/pronúncia, como observado por Alves (2015), fica restrita à aproximação da fala do aprendiz a fala do nativo, o qual é posto em uma posição de referência ou modelo a ser seguido e imitado.

Nessa perspectiva, a ideia de falante nativo reduz-se àquele sujeito que faz uso de uma variedade padrão, o que limita ainda mais um possível intento ao ensino de pronúncia que não se objetive a colonizar o aprendiz. Contudo, ainda nessa esteira que corresponde à não colonização do aprendiz de língua inglesa, faz-se importante ressaltar que, segundo Shin e Kubota (2008), o advento da globalização e os estudos pós-coloniais sobre o ensino de línguas denominadas estrangeiras, instaurou um duplo efeito com relação tanto à homogeneização de um padrão linguístico e cultural, 
quanto à heterogeneização de expressões híbridas ou mais diversificadas e consequentemente mais complexas de identidades.

Assim, mesmo com a celebração de variantes não hegemônicas, e da apropriação da língua inglesa, a fim de se fortalecer o interesse pelo uso do inglês juntamente com a valorização de identidades e contextos locais, o discurso do colonizador continua à interpor-se na fala de professores e aprendizes não nativos, visto que países pertencentes ao chamado inner circle, como Estados Unidos, Reino Unido, Canadá, Austrália e Nova Zelândia, de acordo com o modelo de três círculos do 'World Englishes', desenvolvido por Kachru (1985), são categorizados como normprovinding, ou seja, esses países fornecem a chamada norma ou padrão à ser seguido, visto que eles são classificados como as bases tradicionais do inglês.

Vale destacar, que o modelo de agrupamento das variantes de inglês faladas no mundo criado por Kachru (1985), se torna limitado levando em consideração que tal modelo não acompanha a expansão da língua inglesa até os tempos atuais. No entanto, os países alocados nos outros círculos, outer e expanding circle, ainda são vistos como norm-developing (variante a se desenvolver enquanto norma) e norm-dependent (variante que depende da norma que provém de países do inner circle).

Partindo para as abordagens de ensino de pronúncia nas aulas de inglês para falantes de outras línguas, Morley (1991) sintetiza as principais delas desenvolvidas e praticadas entre os anos quarenta e noventa. Conforme apresentado pela autora, entre as décadas de quarenta e sessenta a pronúncia era considerada como parte importante do ensino de inglês, especialmente para o método audiolingual, que prezava pela precisão na pronúncia da língua por parte do aprendiz que deveria se assemelhar tal qual a de um falante nativo.

No final da década de sessenta até os anos setenta e depois em direção ao início dos anos oitenta, questões a respeito do ensino de pronúncia nas aulas de inglês como segunda língua (doravante L2) retomam fôlego. Ao passo que o número de publicações sobre o ensino de L2 aumenta a preocupação com a pronúncia foi sendo minimizada. Questionava-se, então, se era possível aprender pronúncia na sala de aula sob instrução ou método direto, por meio de imitação ou repetição.

Em oposição tanto à exclusão do ensino de pronúncia, quanto à imitação do que se coloca como falante nativo, Smith e Nelson (1985) apresentam os conceitos de inteligibilidade e compreensibilidade. O compromisso profissional reafirmado nos dias de hoje para capacitar os alunos a se tornarem membros efetivos e plenamente participantes da comunidade falante de língua inglesa nas quais eles se comunicam, é claro quanto à persistência, embora pequena, de um movimento para adicionar a pronúncia de volta à equação instrucional, mas com uma nova visão e uma premissa básica: A pronúncia inteligível é um componente essencial da competência comunicativa. (MORLEY, 1991, p. 489)2

\footnotetext{
${ }^{2}$ No original: Today's renewed professional commitment to empowering students to become effective, fully participant members of the English-speaking community in which they communicate, it is clear that there is a persistent, if small, groundswell of movement to write pronunciation back into the instructional equation but with a new look and a basic premise: Intelligible pronunciation is an essential component of communicative competence. Tradução nossa.
} 
Derwing e Munro (2015) propõem uma revisão ao conceito de inteligibilidade e passam a defini-lo com base na capacidade do ouvinte de entender o significado que o falante deseja transmitir. Nessa definição, entende-se que os autores posicionam um foco maior na percepção do ouvinte com relação ao enunciado produzido pelo aprendiz. Ainda assim, o foco do conceito de inteligibilidade, de maneira geral, continua a se concentrar na clareza e eficácia da comunicação entre o falante aprendiz e o seu interlocutor.

Assim, entende-se que a pronúncia enquanto componente fonéticofonológico da língua deve ter seu ensino integrado às tarefas comunicativas realizadas em sala de aula. Essa integração permite que os aspectos linguísticos referentes a diferentes níveis colaborarem para um resultado satisfatório quanto à efetivação da comunicação relacionada à diferentes temas e principalmente, contextos.

Em uma visão mais contemporânea e com o intuito de resolver as inadequações dos termos mencionados acima, revela-se a importância de se conceituar a língua inglesa como uma língua adicional. Tal conceito amplia a perspectiva do ensino-aprendizagem de inglês, deslocando-o de um lugar distante, ou difícil de acessado por professores e principalmente alunos. A língua adicional caracteriza-se como um acréscimo, ou até mesmo uma extensão da língua a qual o aprendiz já fala, considerando que todos já conhecemos ou falamos ao menos uma língua.

O ensino de pronúncia do inglês inserido na concepção de língua adicional amplia as expectativas de alunos e professores, proporcionando a construção de um diálogo muito mais abrangente que incorpora diferentes visões de mundo alicerçadas na interação em situações de comunicação que propiciem a participação do sujeito que fala e age com o objetivo de ser e de significar em contextos diversos.

\subsection{CRENÇAS SOBRE O ENSINO-APRENDIZAGEM DE PRONÚNCIA}

Após discutirmos sobre o ensino de pronúncia do inglês com base nos conceitos de inteligibilidade e compreensibilidade e ainda sob a luz da concepção de língua adicional, trataremos agora das crenças sobre o ensino-aprendizagem de pronúncia. No campo das pesquisas educacionais é comum encontrarmos diversos trabalhos acerca das crenças sobre ensino-aprendizagem e mais precisamente, sobre crenças de professores. Pesquisas como as de Nespor, (1987); Pajares (1992), Zheng (2009); Borg (2011), citado em Shah et al. (2017) revelam o interesse quanto aos estudos que relacionam crenças dos profissionais docentes à prática em sala de aula.

Contudo, a maioria desses estudos dispõem-se a investigar as crenças de professores à respeito do ensino de habilidades e conteúdos que limitam-se à gramática, leitura e escrita. Segundo Shah et al. (2017), o número de pesquisas que discutem a relação entre crenças e ensino-aprendizagem de pronúncia ainda é relativamente limitado.

Couper (2006) e Saito (2007), também citados por Shah et al., (2017) examinam a influência das crenças de professores sobre o ensino de pronúncia 
relacionando a instrução direta na sala de aula com melhora na clareza da fala de aprendizes a partir dos conceitos de inteligibilidade de compreensibilidade (Derwing, Munro e Wiebe,1998) que dão suporte à relevância do ensino de pronúncia como elemento importante para o desenvolvimento da proficiência dos aprendizes de inglês.

No que tange ainda à importância do ensino de pronúncia, as crenças conduzem papel essencial não somente na prática em sala de aula, mas ainda com relação às escolhas que os profissionais docentes fazem à respeito da variedade a ser ensinada, do material a ser utilizado, que também estão ligadas à fatores externos como o contexto ou ambiente escolar no qual professor e alunos estão inseridos, o currículo da escola, conteúdos programáticos à serem seguidos e muitas vezes a falta de recursos suficientes para as aulas de pronúncia.

\section{AS CRENÇAS DE PROFESSORES EM FORMAÇÃO SOBRE O ENSINO DE PRONÚNCIA}

Considerando os procedimentos necessários para a coleta dos dados que serviriam de base para a nossa análise qualitativa, isto é, que trabalha com trabalha com o universo de significados, motivos, aspirações, crenças, valores e atitudes (MINAYO, 2001), de caráter exploratório, uma vez que buscamos compreensão aprofundada sobre as crenças dos futuros professores (GIL, 2007), elaboramos uma entrevista estruturada em questionário estruturado, aquele no qual o informante responde livremente, de acordo com RAMOS; SANTOS, 2009). O questionário possuía onze perguntas que nos auxiliaram quanto a traçar o perfil dos participantes a serem discutidos mais adiante, além de investigar e identificar as crenças de futuros professores sobre o papel da pronúncia nas aulas de inglês.

Foram selecionados para as entrevistas alunos do curso de Letras da UFRPE - UAST que estivessem cursando as disciplinas de ESO (Estágio Supervisionado Obrigatório), tendo em vista que esses estudantes possuiriam pelo menos a experiência de observação ou ensino de inglês vivenciadas durante os estágios 1, 2 e 3. Os critérios para seleção dos sujeitos envolviam a identificação com o ensino de inglês e a experiência com ensino da língua no próprio ESO ou em atividades de cunho profissional.

As perguntas do questionário, que como já dissemos foram onze, correspondiam a temas que se relacionassem com as crenças comumente expressadas pelos futuros profissionais docentes na condição tanto de aprendizes como de professores em formação. As primeiras perguntas do questionário pretendiam traçar um perfil do grupo de sujeitos da nossa pesquisa em relação ao curso e ao ensino de inglês.

Com relação à motivação para cursar Letras, os oito sujeitos dividem-se entre os que escolheram Letras por afinidade com as áreas de conhecimento do curso (P1, P2, P3, P4 e P6) e os que recorreram à licenciatura em Letras como segunda opção (P5, P7 e P8). No que diz respeito à experiências de ensino propriamente ditas, 
apenas um sujeito (P5) já ensinava inglês antes de cursar a licenciatura, os demais sujeitos alegaram não terem se imaginado professores de inglês.

Avaliando as respostas dos participantes entrevistados, evidencia-se um posicionamento que considera o ensino de pronúncia importante, porém há ainda confusão ou incerteza quanto ao papel ou à função da pronúncia nas aulas de língua inglesa. A defesa do ensino de pronúncia realizada por P2 é apoiada também por P5 e P8, os quais afirmam que este é um fator importante para que o aprendiz seja compreendido de forma mais clara. Em contrapartida, essa compreensão está estritamente amparada na percepção de diferenças entre fonemas consonantais iniciais ou em posição final, como nos chamados pares mínimos, citados por P2, ou ainda na transferência dos sons da língua materna para a língua inglesa, como explicam P2: 'Então, 'night' é pronunciado 'nait'. Só que aí se você muda, sei lá, a pronúncia de alguma das letras, as pessoas não vão entender"; P5: "a gente tem que ensinar que existe uma diferença entre 'cat'e "catch", por exemplo, né? Que isso pode implicar, que isso pode influenciar na hora do entendimento da língua"; e P8: "você tem um 'three', um'free'e um, 'tree'.

Essa visão da pronúncia como eliminação de "dificuldades" que os brasileiros possam enfrentar na pronúncia do inglês encontra respaldo em diferentes vlogs e manuais de ensino de língua, bem como em alguns estudos concentrados no brasileiro falante de inglês, a exemplo de Cristófaro (2019) e Steinberg (2006).

Em seguida, investigamos as crenças dos participantes sobre o uso das variantes hegemônicas nas aulas de língua inglesa, principalmente no que se refere ao ensino de pronúncia. Os participantes deixam clara a crença no uso de uma variante hegemônica como um "norte" ou foco para as aulas de pronúncia, afirmando fazer uso da variante americana padrão: "É, como eu falei, é... eu uso, eu faço uso, muito, do sotaque americano, então eu acho que seria legal ter esse intercâmbio com um sotaque. Tanto para que o aluno saiba o que ele tem que fazer, como ele tem que falar determinada palavra e tudo mais, mas sempre de maneira flexível” (P1).

Com base em tal afirmação, verifica-se que o sujeito investigado não se reconhece enquanto falante não nativo da língua inglesa e, portanto, não reflete sobre a própria variante como sendo não hegemônica, supondo que a flexibilização no ensino de pronúncia com relação à apresentação de outras variantes em sala de aula ainda tenha que estar fundamentada em contextos internacionais. Em contrapartida, P1 e P4 que defendem a flexibilização e a apresentação de outras variantes que não a britânica ou a americana, mas ainda assim pode ser compreendido como um exemplo restritivo por não sair dos chamados inner e outercircle, seguindo o modelo de três círculos do World Englishes de Kachru (1985), considerando apenas as variantes de países que tenham o inglês como língua materna ou língua oficial.

Tendo analisado as crenças dos participantes sobre o uso das variantes hegemônicas, nos concentraremos agora nas respostas dos entrevistados a respeito da prática de ensino de pronúncia. A crença apresentada por P1 sobre o modo como deve ser o ensino de pronúncia está definitivamente relacionada à crença do 
participante quanto à importância desse aspecto linguístico restringindo-se ao campo fonético-fonológico.

Por outro lado, P2, P3, P4 e P5 acreditam que mesmo havendo um momento específico para o ensino de pronúncia, este deve ocorrer de forma contextualizada, através de atividades que instiguem a comunicação como diálogos. Isso está de acordo com as propostas de ensino de pronúncia discutidas por Alves (2015), partindo do entendimento de quanto a pronúncia pode influenciar a comunicação, seja positiva ou negativamente, corroborando a ideia de que atrelar o ensino de tal aspecto linguístico à atividades de comunicação ou produção oral pode resultar na melhora da proficiência dos aprendizes de língua inglesa. Apesar de tal afirmação, P3 compartilha da crença de P2 de que existe uma "pronúncia perfeita" a qual se origina da crença de que os falantes nativos são considerados autoridades da língua

Somando mais uma vez à crença sobre o ensino de pronúncia de forma contextualizada, P6, assim como P7 e P8, falam da importância do desenvolvimento da competência comunicativa dos alunos através de diálogos e de atividades lúdicas, o que pode despertar o interesse do aluno e tornar o ensino de pronúncia menos explícito ou técnico, visando um favorecimento maior do aprendizado.

\section{CONSIDERAÇÕES FINAIS}

Em conformidade com os resultados apresentados e discutidos, verificamos que as crenças dos oito professores em formação do curso de Letras da UFRPE UAST a respeito do papel da pronúncia nas aulas língua inglesa assemelham-se principalmente quanto à importância do ensino do componente fonético-fonológico, tendo em vista que, grosso modo, todos os participantes reconheceram direta ou indiretamente que o referido aspecto linguístico pode influenciar na clareza da comunicação entre aprendiz e interlocutor.

Entretanto, ao retornarmos à primeira pergunta da pesquisa: "Quais crenças os futuros professores de inglês formados pela UFRPE-UAST sustentam a respeito da pronúncia da língua inglesa, enquanto falantes não nativos do idioma?”, observamos que os participantes compreendem a pronúncia a partir da divisão, distanciamento, ou ainda do isolamento dos chamados aspectos segmentais (sons/fonemas) e suprassegmentais (entonação, ritmo), pautando essa clareza da comunicação apenas na articulação de sons da língua inglesa, visando uma certa precisão na fala do aprendiz, ainda que alguns defendam um ensino de pronúncia contextualizado.

A segunda pergunta direcionava nossa investigação acerca das crenças sobre variantes específicas do inglês: "As crenças dos professores se relacionam a comportamentos prescritivos de variantes da língua inglesa?”. Considerando a nossa análise com base nos dados coletados constatou-se que os participantes mantêm a crença que deve-se fazer uso de uma variante hegemônica (britânica ou americana) em sala de aula, o que reforça a crença da pergunta anterior de que o ensino de 
pronúncia deve concentrar o foco na articulação dos sons do inglês, tomando por base o uso de uma variante à ser vista como "guia" ou "norte".

Por fim, a terceira e última pergunta da pesquisa buscava identificar e obter respostas quanto às crenças dos entrevistados sobre o uso da própria variante: "Quais as crenças que futuros professores de línguas mantêm sobre suas próprias pronúncias?". Portanto, ao observarmos novamente nossa análise, evidenciamos que mesmo que haja uma menção sobre a própria variante baseando-se no contexto local ou regional por parte de alguns entrevistados, notou-se claramente que os participantes não se percebem enquanto falantes não nativos, afirmando fazer uso, como discutido acima, de uma variante hegemônica, deixando de refletir de maneira mais aprofundada sobre a sua variante e como essa pode dialogar com as dos seus alunos objetivando-se a construir uma identidade pessoal e cultural mais forte e distanciada dos discursos hegemônicos, normativos ou colonizadores.

\section{REFERÊNCIAS}

ALMEIDA FILHO, José Carlos Paes de. Dimensões comunicativas no ensino de línguas. Campinas, SP: Pontes, 1993.

ALVES, Ubiratã Kickhöfel. Ensino de pronúncia na sala de aula de língua estrangeira: questões de discussão a partir de uma concepção de língua como sistema adaptativo e complexo. Versalete, v. 3, p. 392-413, 2015.

BARCELOS, Ana Maria Ferreira. Understanding teachers' and students' language learning beliefs in experience: A Deweyan Approach. Tese de doutorado. The University of Alabama, Tuscaloosa, AL, USA, 2000.

BARCELOS, Ana Maria Ferreira. Crenças sobre aprendizagem de línguas, linguística aplicada e ensino de línguas. Linguagem \& Ensino, Pelotas, v. 7, n. 1, p. 123-156, 2004.

BOTASSINI, Jacqueline Ortelan Maia. A importância dos estudos de crenças e atitudes para a Sociolinguística. SIGNUM: Estud. Ling., Londrina, no 18/1, Jun. 2015, p. 102-131.

CRISTOFARO-SILVA, Thaís. Pronúncia do Inglês para Falantes do Português Brasileiro. SP: Contexto, 2019.

FREEMAN, Donald; JOHNSON, Karen. Reconceptualizing the knowledge-base of language teacher education. In: TESOL Quarterly, 32, 1998, p. 397 - 417.

GERHARDT, Tatiana Engel et al. Estrutura Do Projeto De Pesquisa. In: RAMOS, Gerhardt, T.E. e Silveira, D. T. (org.) Métodos de pesquisa. Porto Alegre: Editora da UFRGS, 2009.

GIL, Antônio Carlos. Como elaborar projetos de pesquisa. 4. ed. São Paulo: Atlas, 2007.

GUIMARÃES, Henrique Manuel. Concepções, crenças e conhecimento - afinidades e distinções essenciais. In: Quadrante, Vol XIX, n. ${ }^{\circ}$ 2, 2010, p. 81-102

HORWITZ, Elaine. Surveying students' beliefs about language learning. In:

WENDEN, Anita; RUBIN, Joan. (Ed.). Learner strategies in language learning. Londres, Prentice Hall International, 1987, p. 110-129.

KACHRU, Braj Bihari.Standards, codification, and sociolinguistic realism: The English language in the outer circle. In: QUIRK, Randolph; WIDDOWSON, Henry. English in the World: Teaching and Learning the language and the literature. Cambridge: Cambridge University Press, 1985.

LALLANDE, A. Vocabullaire tecnique et critique de Philosophie. Paris: PUF, 1976. 
LEFFA, Vilson José. A look at students' concept of language learning. In: Trabalhos em Lingüística Aplicada, Campinas, n. 17, p. 57-65, 1991.

LORTIE, Dan. School teacher: A sociological study. Chicago: The University of Chicago Press, 1985

MINAYO, M. C. S. (Org.). Pesquisa social: teoria, método e criatividade. Petrópolis: Vozes, 2001.

MORLEY, Joan. The Pronunciation Component in Teaching English to Speakers of Other Languages. In: TESOL QUARTERLY, Vol. 25, No. 3, 1991.

MUNRO, Murray; DERWING, Tracey. A prospective for pronunciation research in the 21st century: A point of view. In: Journal of Second Language Pronunciation, 2015, p. $11-42$.

PAJARES, Frank. Teachers' beliefs and educational research: Cleaning up a messy construct. In: Review of Educational Research, v. 62, n. 3, p. 307-332, 1992.

ROKEACH, Milton. Beliefs, attitudes and values: A theory of organization and change. São Francisco: Jossey Bass, 1976.

STEINBERG, Martha. Inglês Norte Americano Pronúncia e Morfologia. SP: Nova Alexandria, 2006.

SHAH, Shanina Sharatol Ahmad; OTHMAN, Juliana; SENOM, Fatiha. The Pronunciation componentin ESL Lessons: Teachers' Beliefsand Practices. In: Indonesian Journal of Applied Linguistics, v. 6, n. 2, p. 193-203,2017.

SHIN, Hyungjung; KUBOTA, Ryuko.Post-colonialism and globalization in language education. In: SPOLSKY, B.; HULT, F. The handbook of educational linguistics, Oxford: Blackwell, 2008, p. $206-219$.

VILLANI, Fábio Luiz. O efeito da crença dos professores de língua inglesa na escola pública. In: Revista Múltiplas Leituras, v.1, n. 2, p. 141-155, 2008.

Recebido em: 28/02/2019

Aprovado em: 07/06/2019

Publicado em: 19/12/2019 